\title{
Endovascular Rescue for Renal Artery Pseudoaneurysms following Minimally Invasive Robot-Assisted Partial Nephrectomy-A Case Series
}

\author{
Nagateja Bonala1 Vidya Bhargavi ${ }^{1}$ Indushekhar Subbanna ${ }^{1}$ Bharath KS ${ }^{1}$ Rajkumar Patel ${ }^{2}$ \\ ${ }^{1}$ Department of Interventional Radiology, HCG Hospital, Bengaluru, \\ Karnataka, India \\ 2 Department of Uro-oncology and Robotic Surgery, HCG Hospital, \\ Bengaluru, Karnataka, India \\ Address for correspondence Nagateja Bonala, MD, Department of \\ Interventional Radiology, HCG Hospital, Bengaluru, Karnataka \\ 560027, India (e-mail: nagateja@gmail.com).
}

J Clin Interv Radiol ISVIR 2022;6:212-216.

\section{Introduction}

Robotic partial nephron sparing surgery (RPN) offers a minimally invasive surgical option, especially for patients presenting with smaller renal mass, and is being employed recently even for larger and complex lesions. ${ }^{1}$ Postoperative massive hemorrhage, urine leak, and urinoma formation are few of the known complications following RPN. Renal artery pseudoaneurysms (RAP) are a relatively rare complication following nephron sparing surgery. ${ }^{2}$ Development of RAP has been reported to be seen in the immediate postoperative period and also as a delayed presentation ( $>3$ weeks). ${ }^{2}$ With increasing utilization of nephron sparing surgery, the incidence is expected to be on rise. Here, we present a series of four cases presenting with RAP following RPN treated with super-selective endovascular measures with aim to preserve as much normal renal tissue as possible without jeopardizing the nephron sparing nature of surgery.

\section{Case 1}

A 62-year-old diabetic and hypertensive male presenting with multiple vomiting episodes was found to have an exophytic mass in the interpolar region of right kidney. Imaging showed no vascular thromboses and no distant metastases. He underwent RPN. Renorrhaphy was done in two layers. Warm ischemic time of 20 minutes and estimated blood loss (EBL) of $150 \mathrm{~mL}$, RENAL score ${ }^{3} 9$ xh were noted. On postoperative day 17 , he presented with high-grade fever, chills, multiple episodes of vomiting, and generalized weakness. He was investigated and was found to have leukocytosis and hyponatremia. Despite aggressive medical treatment, he article published online February 11, 2022
DOI https://doi.org/ 10.1055/s-0041-1741528. ISSN 2457-0214.
(C) 2022. Indian Society of Vascular and Interventional Radiology. All rights reserved.

This is an open access article published by Thieme under the terms of the Creative Commons Attribution-NonDerivative-NonCommercial-License, permitting copying and reproduction so long as the original work is given appropriate credit. Contents may not be used for commercial purposes, or adapted, remixed, transformed or built upon. (https://creativecommons.org/ licenses/by-nc-nd/4.0/)

Thieme Medical and Scientific Publishers Pvt. Ltd., A-12, 2nd Floor, Sector 2, Noida-201301 UP, India 
had high-grade fever and one episode of gross hematuria resulting in drop in hemoglobin levels. After being transfused with two units of packed cell red blood cells, he was taken up for angiography.

Angiogram of the right renal artery through a $5 \mathrm{~F}$ vascular sheath (Radifocus Introducer II Standard Kit A, Terumo Medical Corporation, United States) and 4F Cobra C1 catheter (Glidecath, Terumo Medical Corporation, Corporation 265 Davidson Avenue Somerset, NJ 08873, United States) showed $23 \times 19 \mathrm{~mm}$ pseudoaneurysm in the interpolar region. Super-selective embolization was done using 2.4F microcatheter (Direxion, Boston Scientific Corporation, United States) and microcoil of size $5 \mathrm{~mm}$ $\times 7 \mathrm{~cm}$ (Nester Embolization coil, Cook Medical LLC, United States). Postembolization angiogram showed no filling of the pseudoaneurysm ( - Fig. 1). Patient was eventually discharged in a satisfactory condition with no similar episodes later.

\section{Case 2}

Screening ultrasonography (USG) of a 43-year-old male detected an incidental left renal mass that on contrast enhanced computerized tomography (CT) was a well-defined heterogeneously enhancing lesion in the interpolar region of left kidney suggesting a neoplasm, renal cell carcinoma. Patient underwent RPN. Renorrhaphy was done in two layers. Warm ischemia time of 34 minutes and EBL of $200 \mathrm{~mL}$, and renal score 10X were noted. Nineteen days after the surgery, patient had few episodes of fever, dysuria, and hematuria. Patient was evaluated with CT renal angiogram and was found to have a pseudoaneurysm.

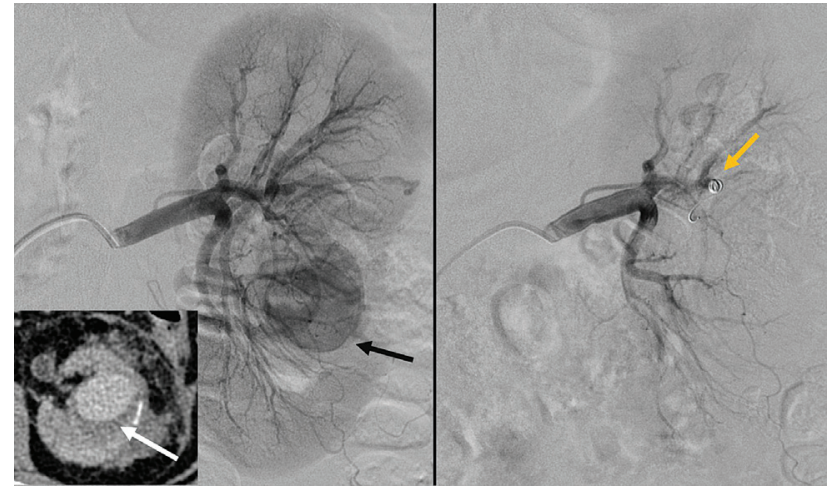

Fig. 2 Catheter angiography (black arrow) and computed tomography angiography image (white arrow) showing large saccular pseudoaneurysm in the interpolar region of left kidney. Angiography image post-super-selective embolization using microcoil (yellow arrow) shows absence in supply to the pseudoaneurysm.

He was referred to the department of interventional radiology for further management. Angiogram of the left renal artery showed active contrast extravasation from the segmental branch in the interpolar region, which was seen to fill a large, $22 \times 11 \mathrm{~mm}$ pseudoaneurysm (-Fig. 2). Superselective embolization was done using $2.7 \mathrm{~F}$ microcatheter (Progreat, Terumo Medical Corp., United States), 0.2 cc of $n$ butyl cyanoacrylate (NBCA) glue with lipiodol in the ratio of $1: 2$ and a coil of size $3 \mathrm{~mm} \times 5 \mathrm{~cm}$. Postembolization angiogram showed no active contrast extravasation and no filling of pseudoaneurysm (-Fig. 2). Patient was followed up till 8 months and had no similar episodes.
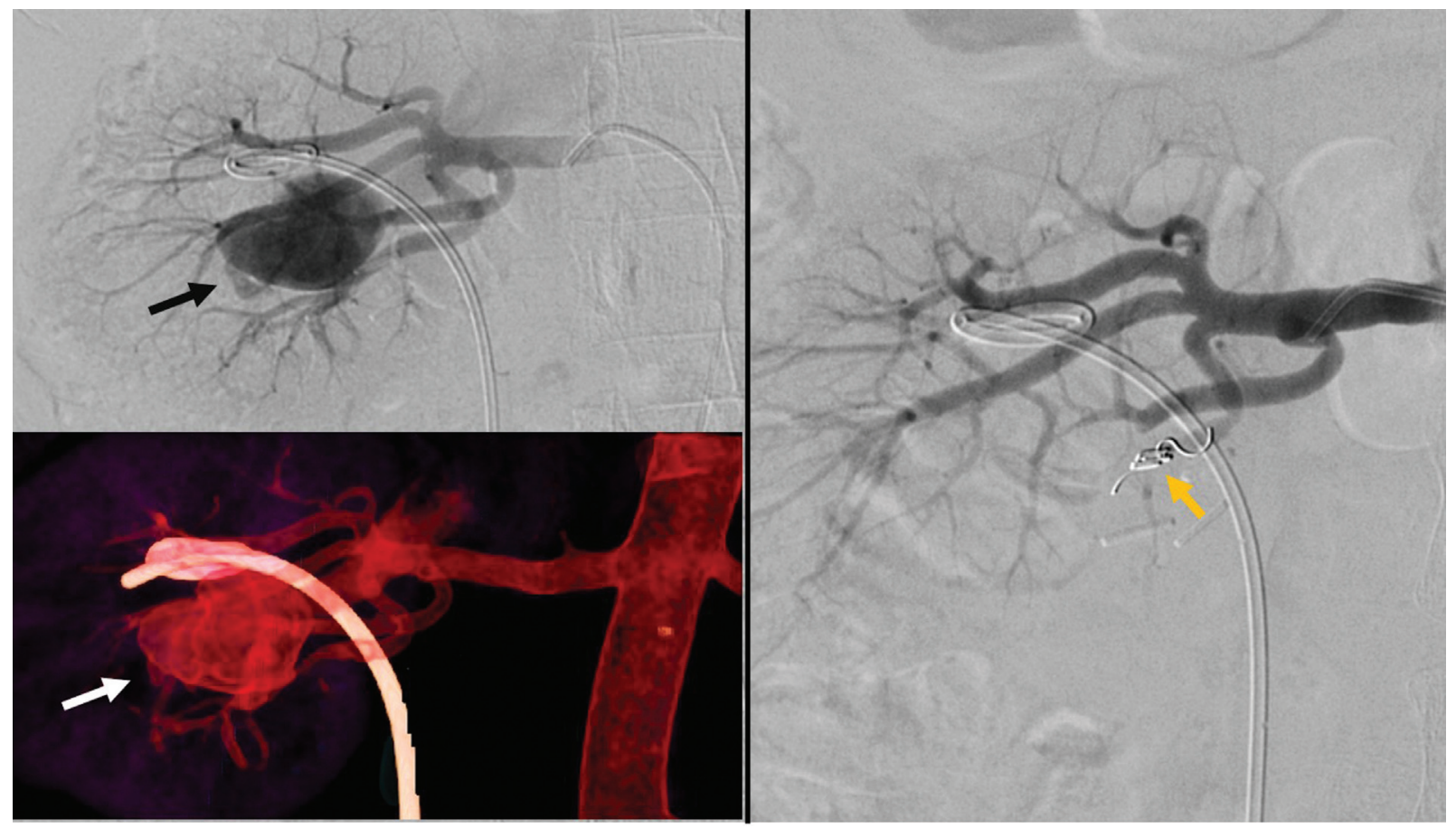

Fig. 1 Catheter angiography (black arrow) and computed tomography volume-rendering technique image (white arrow) showing large saccular pseudoaneurysm in the interpolar region of right kidney. Angiography image post-super-selective embolization using microcoil (yellow arrow) shows no filling up of pseudoaneurysm. 


\section{Case 3}

Routine health screening of a 43-year-old male revealed bilateral renal mass on USG. Contrast-enhanced CT (CECT) showed a $4.6 \times 4.6 \mathrm{~cm}$ well-defined mass in the interpolar region of left kidney involving cortex and medulla with no vascular thromboses and a similar smaller $1.9 \times 1.8 \mathrm{~cm}$ lesion in the upper pole of right kidney. Patient underwent RPN for the left renal mass. Renography was done in two layers. Warm ischemic time of 35 minutes and EBL of $150 \mathrm{~mL}$, and RENAL score $10 \mathrm{~h}$ were noted. Fourteen days after the surgery, patient presented with complaints of dysuria, fever, and hematuria. Patient was referred for angiography.

Angiogram of the left renal artery showed actively filling multiple pseudoaneurysms from the anteroinferior and posterior segmental branches in the lower and interpoles, largest measuring $22 \times 11 \mathrm{~mm}$. Super-selective embolization of anteroinferior branches was done using $2.7 \mathrm{~F}$ microcatheter and coils of size $6 \mathrm{~mm} \times 7 \mathrm{~cm}$ and $4 \mathrm{~mm} \times 7 \mathrm{~cm}$. Posterior segmental branches were super-selectively embolized subsequently with coils of size $3 \mathrm{~mm} \times 3 \mathrm{~cm}$ and $5 \mathrm{~mm} \times 5 \mathrm{~cm}$. Technical success was confirmed with a postembolization angiogram showing no contrast extravasation (-Fig. 3). Clinical success was confirmed with no episodes of hematuria, fever, and dysuria on follow-up beyond 6 months.

\section{Case 4}

A 58-year-old male with complaints of abdominal pain was evaluated with CECT to have multiple left renal mass lesions. CT reported a lesion of size $3.6 \times 3.6 \mathrm{~cm}$ on the medial aspect and a smaller $1.1 \times 1.1 \mathrm{~cm}$ lesion in the later aspect of lower pole region of left kidney. He underwent left RPN. During the procedure, surgeons found a large lower pole tumor with two smaller partially exophytic small tumors nearby. Doublelayered renorrhaphy was done. Warm ischemic time of 45 minutes and approximate blood loss of $100 \mathrm{~mL}$, and RENAL score $10 \mathrm{x}$ were noted. Patient had an uneventful postoperative period. On day 42 , after the surgery, patient

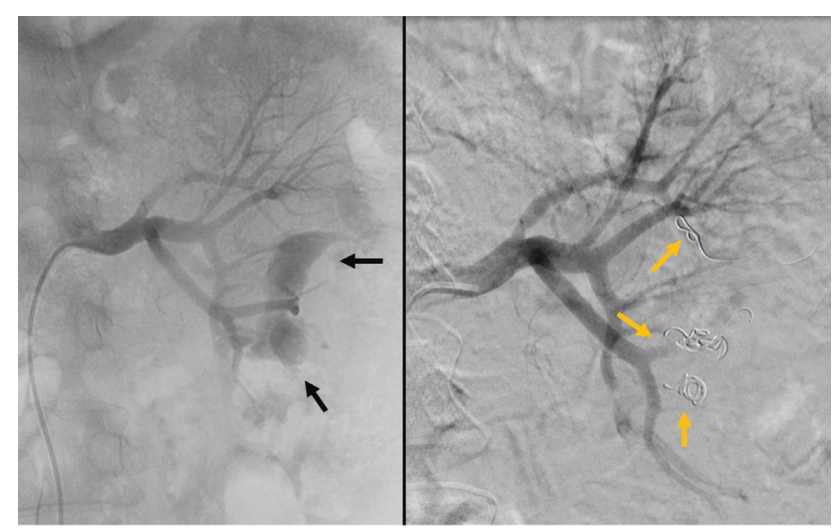

Fig. 3 Catheter angiography showing multiple large pseudoaneurysms (black arrows) in the lower and interpolar region of left kidney. Angiography image post-super-selective embolization using multiple microcoils (yellow arrows) shows arrest in filling up of pseudoaneurysm. complained of hematuria and blood clots in urine for 3 days. USG of the abdomen showed a focal heterogenous isoechoic area measuring $65 \times 58 \mathrm{~mm}$ with no internal vascularity at postoperative site abutting the mid pole of remnant left kidney, likely a hematoma.

Angiogram of the left renal artery showed active contrast extravasation from inferior segmental branches in the lower pole region to fill a large, $40 \times 20 \mathrm{~mm}$ saccular pseudoaneurysm. Super-selective embolization was done using three coils of sizes $4 \mathrm{~mm} \times 14 \mathrm{~cm}, 4 \mathrm{~mm} \times 7 \mathrm{~cm}$, and $3 \mathrm{~mm} \times 7 \mathrm{~cm}$. Postembolization angiogram showed no active contrast extravasation (-Fig. 4). Patient was stable with no hematuria post procedure. All the cases have been summarized in - Table 1 .

\section{Discussion}

RAP is one of the most common vascular complications with etiologies ranging from trauma, iatrogenic causes like percutaneous biopsy, nephrostomy, and following surgical procedures like partial nephrectomy. ${ }^{4}$

Yamashita et al in their prospective study reported a significant $18 \%$ incidence of RAP following RPN. However, the study showed that smaller $(<10 \mathrm{~mm})$ asymptomatic pseudoaneurysms can be managed conservatively and may resolve spontaneously. On the other hand, symptomatic and larger lesions need to be promptly intervened, failing which can even result in renal failure over time. ${ }^{5}$

All our patients with complex tumor, represented by higher RENAL nephrometry scores, are counseled about potential vascular complications and with informed consent are taken up for RPN. They are alerted about the warning signs like gross hematuria, and signs of infection at the time of discharge and are instructed to report immediately in such instances. The reported time interval between the surgery and development of a symptomatic pseudoaneurysm has varied widely ranging from 1 to 4 weeks. A study that reviewed almost a thousand cases of minimally invasive partial nephrectomy reported no case presenting after 25 days. $^{6}$ In our series, three patients presented within 21 days and only one patient presented late after 39 days. Affirmative reason for development of RAP is still a matter of

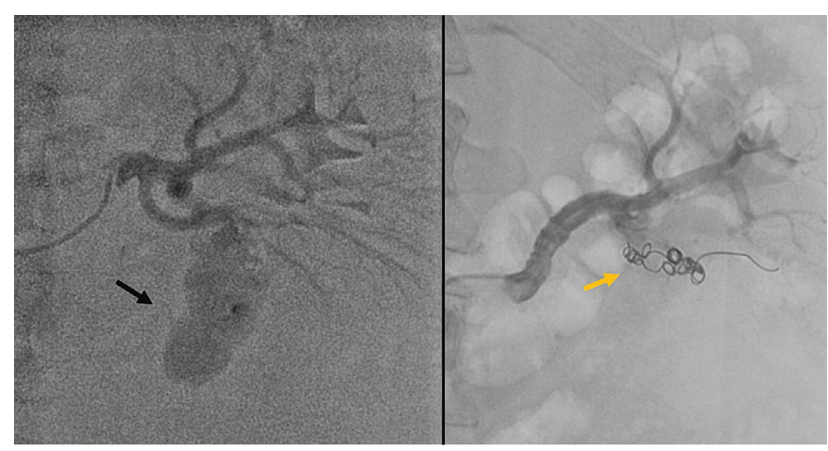

Fig. 4 Catheter angiography shows large saccular pseudoaneurysms (black arrow) in the lower pole region of left kidney. Angiography image post-super-selective embolization using microcoils (yellow arrow) shows the desired result. 
Table 1 Summary of findings in the patients who underwent robot-assisted partial nephrectomy

\begin{tabular}{|l|l|l|l|l|l|l|l|l|}
\hline SI. no & $\begin{array}{l}\text { Location of } \\
\text { the renal } \\
\text { mass }\end{array}$ & $\begin{array}{l}\text { RENAL } \\
\text { nephrometry } \\
\text { score } \\
\text { of the } \\
\text { lesion }\end{array}$ & $\begin{array}{l}\text { Renorrhaphy } \\
\text { (layers) }\end{array}$ & $\begin{array}{l}\text { Estimated } \\
\text { blood loss } \\
\text { (mL) }\end{array}$ & $\begin{array}{l}\text { Warm } \\
\text { ischemia } \\
\text { time } \\
\text { (minutes) }\end{array}$ & $\begin{array}{l}\text { Time interval } \\
\text { after surgery } \\
\text { and symptoms }\end{array}$ & $\begin{array}{l}\text { Symptoms } \\
\text { at the } \\
\text { time of } \\
\text { presentation }\end{array}$ & $\begin{array}{l}\text { Endovascular } \\
\text { embolic } \\
\text { agent(s) used }\end{array}$ \\
\hline 1. & $\begin{array}{l}\text { Right-interpolar } \\
\text { region }\end{array}$ & $9 x h$ & 2 & 150 & 20 & 17 days & $\begin{array}{l}\text { Fever, chills, } \\
\text { vomiting, weakness }\end{array}$ & Coils \\
\hline 2 & $\begin{array}{l}\text { Left-interpolar } \\
\text { region }\end{array}$ & $10 \mathrm{x}$ & 2 & 200 & 34 & 19 days & $\begin{array}{l}\text { Fever, dysuria, } \\
\text { hematuria }\end{array}$ & NBCA and coils \\
\hline 3. & $\begin{array}{l}\text { Left-interpolar } \\
\text { region }\end{array}$ & $10 \mathrm{~h}$ & 2 & 150 & 35 & 14 days & $\begin{array}{l}\text { Fever, dysuria, } \\
\text { hematuria }\end{array}$ & Coils \\
\hline 4. & \begin{tabular}{l} 
Left-lower pole \\
\hline
\end{tabular} & $10 \mathrm{x}$ & 2 & 100 & 45 & 39 days & $\begin{array}{l}\text { Hematuria, } \\
\text { clots in urine. }\end{array}$ & Coils \\
\hline
\end{tabular}

Abbreviations: A, anterior/posterior; E, exophytic/endophytic; L, location of tumor relative to polar lines; $\mathrm{N}$, nearness of tumor to collecting system or a sinus; $R$, radius.

RENAL score components. ${ }^{3}$

Table 2 Preferred embolic agent for the management of various causes of hemorrhage

\begin{tabular}{|l|l|l|}
\hline Type of hemorrhage & Angiographic finding & $\begin{array}{l}\text { Choice of } \\
\text { embolizing agent }\end{array}$ \\
\hline Pseudoaneurysm & $\begin{array}{l}\text { Contrast filling of an irregular outpouching in } \\
\text { communication with vessel lumen }\end{array}$ & Coils \\
\hline $\begin{array}{l}\text { Pseudoaneurysm with } \\
\text { active extravasation }\end{array}$ & $\begin{array}{l}\text { Contrast filling of an irregular outpouching in } \\
\text { communication with vessel lumen associated with brisk } \\
\text { contrast extravasation }\end{array}$ & Coils and/or NBCA (glue) \\
\hline $\begin{array}{l}\text { Arteriovenous or } \\
\text { arteriocalyceal fistula }\end{array}$ & $\begin{array}{l}\text { Early filling of vein/calyx adjacent to the } \\
\text { contrast-opacified artery and could be associated with } \\
\text { a pseudoaneurysm }\end{array}$ & NBCA (glue) \\
\hline
\end{tabular}

Abbreviation: NBCA, n-butyl cyanoacrylate.

debate, including but not limited to arterial transection, partial ligation of a small distal order branch, or missed ligation of branch in spasm, redirecting the suture needle while approximating the parenchymal defect of partial nephrectomy and longer operative and cold ischemia times. Technical caveats in surgery have been suggested to avoid potential cause for bleeding post-RPN. ${ }^{1,2,7-9}$

Catheter angiography and selective embolization have been established as the main course of treatment for patients presenting with hematuria, bleeding into the surgical drain, sudden onset abdomen and/or flank pain, refractory hypotension, tachycardia and drop in levels of hemoglobin following open or laparoscopic partial nephrectomy. ${ }^{10}$ The purpose of minimal invasive nephron sparing surgery is to preserve the renal function.

Anatomy of renal artery and its divisions reveals that renal artery originating from abdominal aorta divides into anterior and posterior divisions. Anterior division further dividing into apical, upper, middle, and lower segmental arteries and the posterior division continues as posterior segmental artery with no collaterals/anastomoses between the segments rendering them as end arteries. Variations in origins of segmental arteries apart from the variations in origin and presence of accessory renal arteries have also been reported and must be identified on angiograms to avoid incomplete/erroneous embolization. ${ }^{11}$ Portion of the renal parenchyma supplied by the segmental artery can be isolated and managed independently without affecting the other segments if embolization is done super-selectively engaging the segmental branches. Additionally, review of preoperative CT angiogram and use of intraoperative cone beam CT can help in identifying bleeding sites and can help in isolating the involved segments. ${ }^{12}$

With a wide variety of embolic agents available currently, preferred agent for management of different types of hemorrhage is indicated in - Table 2. ${ }^{13,14}$ Endoluminal stent-graft (covered stent) can be used to isolate the pseudoaneurysm and percutaneous USG-guided thrombin/ NBCA injection can be attempted in a failed endovascular rescue. $^{15}$

Studies have dismissed any apprehensions of renal artery embolization causing renal function failure and have shown to cause no long-term adverse effect on the renal function and blood pressure control. ${ }^{16}$

In conclusion, development of pseudoaneurysms postRPN is not an unknown entity but careful evaluation of preoperative imaging, multidisciplinary team meetings, accurate identification of origin of hemorrhage/ pseudoaneurysm, and super-selective segmental approach to endovascular management would result in preserving as much as functional renal parenchyma as well as rescue the patient from fatal hemorrhagic complication. 


\section{Conflict of Interest \\ None declared.}

\section{References}

1 Connor J, Doppalapudi SK, Wajswol E, et al. Postoperative complications after robotic partial nephrectomy. J Endourol 2020;34 (01):42-47

2 Verges DP, Margules A, Weprin S, Ferenczi B, Lallas CD. Delayed renal artery pseudoaneurysm after robotic partial nephrectomy. J Robot Surg 2017;11(02):275-277

3 Kutikov A, Uzzo RG. The R.E.N.A.L. nephrometry score: a comprehensive standardized system for quantitating renal tumor size, location and depth. J Urol 2009;182(03):844-853

4 Netsch C, Brüning R, Bach T, Gross AJ. Management of renal artery pseudoaneurysm after partial nephrectomy. World J Urol 2010; 28(04):519-524

5 Yamashita S, Kawabata H, Deguchi R, et al. Natural history of asymptomatic pseudoaneurysm soon after robot-assisted partial nephrectomy: single-center prospective study. Urology 2021;148 (148):145-150

6 Chavali JSS, Bertolo R, Kara O, et al. Renal arterial pseudoaneurysm after partial nephrectomy: literature review and singlecenter analysis of predictive factors and renal functional outcomes. J Laparoendosc Adv Surg Tech A 2019;29(01):45-50

7 Delto JC, Chang P, Hyde S, McAnally K, Crociani C, Wagner AA. Reducing pseudoaneurysm and urine leak after robotic partial nephrectomy: results using the early unclamping technique. Urology 2019;132:130-135

8 Tohi Y, Murata S, Makita N, et al. Absence of asymptomatic unruptured renal artery pseudoaneurysm on contrast-enhanced computed tomography after robot-assisted partial nephrectomy without parenchymal renorrhaphy. Asian J Urol 2020;7(01): 24-28

9 Singh D, Gill IS. Renal artery pseudoaneurysm following laparoscopic partial nephrectomy. J Urol 2005;174(06):2256-2259

10 Jeon CH, Seong NJ, Yoon CJ, Byun SS, Lee SE. Clinical results of renal artery embolization to control postoperative hemorrhage after partial nephrectomy. Acta Radiol Open 2016;5(08):2058460 116655833

11 Rani N, Singh S, Dhar P, Kumar R. Surgical importance of arterial segments of human kidneys: an angiography and corrosion cast study. J Clin Diagn Res 2014;8(03):1-3

12 Grosse U, Syha R, Ketelsen D, et al. Cone beam computed tomography improves the detection of injured vessels and involved vascular territories in patients with bleeding of uncertain origin. Br J Radio 2018;91(1088):20170562

13 Chiramel GK, Keshava SN, Moses V, Kekre N, Tamilarasi V, Devasia A. Clinical outcomes of endovascularly managed iatrogenic renal hemorrhages. Indian J Radiol Imaging 2015;25(04):380-390

14 Wilkins LR, All J, Angle FJ. Transcatheter Embolization for Trauma of the Pelvis. Endovascular today 2014:60-67. Accessed December 17, 2021: https://evtoday.com/articles/2014-sept/transcatheter-embolization-for-trauma-of-the-pelvis

15 NEA Saad, Wael ESaad, Mark GDavies, David LWaldman, Patrick JFultz, Deborah JRubens. Pseudoaneurysms and the role of minimally invasive techniques in their management. Radiographics 2005;25(Suppl 1):S173-S189

16 Collins CS, Eggert CH, Stanson AJ, Garovic VD. Long-term followup of renal function and blood pressure after selective renal arterial embolization. Perspect Vasc Surg Endovasc Ther 2010; 22(04):254-260 